\title{
Impact of cafeteria feeding during lactation in the rat on novel object discrimination in the offspring
}

\author{
Thomas M. Wright ${ }^{1}$, Madeleine V. King ${ }^{2}$, William G. Davey ${ }^{1}$, Simon C. Langley-Evans ${ }^{3}$ and \\ Jörg-Peter W. Voigt ${ }^{1 *}$ \\ ${ }^{1}$ School of Veterinary Medicine and Science, University of Nottingham, Sutton Bonington Campus, \\ Loughborough LE12 5RD, UK \\ ${ }^{2}$ School of Life Sciences, University of Nottingham Medical School, Queen's Medical Centre, Nottingham NG7 $2 U H$, UK \\ ${ }^{3}$ School of Biosciences, University of Nottingham, Sutton Bonington, Loughborough LE12 5RD, UK
}

(Submitted 25 February 2014 - Final revision received 20 August 2014 - Accepted 29 August 2014 - First published online 27 October 2014)

\section{Abstract}

There is increasing evidence that hyperenergetic diets have an impact on memory in rodents. However, it is largely unknown how diets, such as a cafeteria diet (CD), that mimic a Western-type diet act on learning and memory, in particular when fed during early stages of development. Here, we fed lactating dams a CD and exposed both male and female offspring to a novel object discrimination (NOD) task, a two-trial test of recognition memory in which rats exposed to two identical objects during a training/familiarisation trial can discriminate a novel from a familiar object during the subsequent choice trial. The choice trial was performed following inter-trial interval (ITI) delays of up to $4 \mathrm{~h}$. Maternal diet did not have an impact on exploration of the objects by either sex during the familiarisation trial. Control males discriminated the novel from the familiar object, indicating intact memory with an ITI of $1 \mathrm{~h}$, but not 2 or $4 \mathrm{~h}$. The CD delayed this natural forgetting in male rats such that discrimination was also evident after a $2 \mathrm{~h}$ ITI. In contrast, control females exhibited discrimination following both 1 and $2 \mathrm{~h}$ ITI, but the CD impaired performance. In summary, the present study shows that maternal exposure to the CD programmes NOD in the adult. In better-performing females, dietary programming interferes with NOD, whereas NOD was improved in males after lactational CD feeding.

\section{Key words: Cafeteria diet: Rats: Nutritional programming: Memory: Novel object discrimination: Sex differences}

Chronic exposure of rodents to hyperenergetic diets can impair learning and memory ${ }^{(1,2)}$. Such diet-induced memory impairments have largely been shown for hippocampaldependent spatial tasks and less so for perirhinal-dependent object discrimination $^{(3-10)}$. There is some evidence that obesity induced by chronic sucrose or high fat feeding to rats impairs performance in object recognition memory tests that measure the extent to which animals can discriminate between novel and familiar objects ${ }^{(11,12)}$. Therefore, it is well established that obesogenic diets influence a range of behaviours in rats. There is now great interest in knowing whether exposure to similar diets during early life can have similar effects. A number of studies have focused upon exposures during fetal life or early-neonatal stages. In rats, maternal obesity, due to overfeeding, can impair reversal learning ${ }^{(13)}$. Interestingly, and in contrast to the detrimental effects of adult high-fat diet feeding ${ }^{(2)}$, maternal obesity had a positive impact on spatial water-maze learning in the offspring when tested in adulthood ${ }^{(14)}$. In contrast, maternal obesity due to high fat feeding seems to interfere with operant learning in adulthood $^{(15)}$ and spatial learning is also impaired in the offspring from obese mice ${ }^{(16)}$.

While the effects of early-life exposure to high-fat or highsugar diets have been documented, less is known about the behavioural effects of Western-type diets such as the cafeteria diet $(\mathrm{CD})^{(17-20)}$. The $\mathrm{CD}$, when compared with a high-fat diet, is particularly effective in modelling obesity-related metabolic abnormalities ${ }^{(21)}$. A direct comparison of the CD and a high-fat diet also revealed differences in their effects on memory, suggesting differences between these diets beyond the induction of obesity ${ }^{(22)}$. Early developmental stages are a sensitive period for inducing long-lasting effects of cafeteria feeding on metabolism ${ }^{(23-25)}$. However, little is currently known about the behavioural effects of early cafeteria feeding. A study by White et al. ${ }^{(22)}$ has demonstrated that exposure to the $\mathrm{CD}$ or a high-fat diet had different sensitising effects

Abbreviations: CD, cafeteria diet; ITI, inter-trial interval; NOD, novel object discrimination.

*Corresponding author: J.-P. W. Voigt, fax +44 115 9516440, email peter.voigt@nottingham.ac.uk 
on water-maze retention following a re-exposure to the same diet in adulthood. We have recently demonstrated that early, in particular lactational, cafeteria feeding does not only programme a pre-obese state in adult offspring, but also programmes feeding behaviour and anxiolysis when tested between 10 and 15 weeks of age ${ }^{(26,27)}$. However, beyond programming of satiety regulation and anxiolysis, it remains unknown whether lactational exposure to the CD has an impact on non-spatial memory. Therefore, the present study explored the consequences of lactational CD feeding on recognition memory in adult offspring. Memory was tested in a novel object discrimination (NOD) paradigm. Originally devised by Ennaceur \& Delacour ${ }^{(12)}$, the NOD procedure has been widely utilised to investigate the impact of genetic, physiological and pharmacological manipulations on recognition memory in rodents (for a review, see Dere et $a l .{ }^{(28)}$ ), and also proved sensitive to nutritional manipulations ${ }^{(4,11)}$. In contrast to the water-maze task, the NOD test does not involve high levels of stress or anxiety. In high-arousal memory tests, anxiolytic effects of hyperenergetic diets ${ }^{(29)}$ can contribute to diet-induced memory impairment ${ }^{(30)}$. Our previous finding that lactational CD feeding programmes anxiolytic effects in the offspring ${ }^{(27)}$ would therefore preclude the aversive water-maze task as a test of choice. As direct exposure of rats to hyperenergetic diets has been reported to induce memory deficits, it was hypothesised that maternal exposure to $\mathrm{CD}$ feeding might induce a deficit in recognition memory in adult offspring.

\section{Experimental procedures}

Pregnant female Wistar rats (Harlan) were housed individually with ad libitum access to a standard laboratory chow (Teklad Global 18\%; Harlan) and water. The rats were maintained under a $12 \mathrm{~h}$ light $-12 \mathrm{~h}$ dark cycle (lights on 08.00 hours), between 20 and $22^{\circ} \mathrm{C}$. At birth, litters were reduced to four pups of each sex, and randomly allocated to either a standard laboratory chow diet (control) or the same chow diet in conjunction with the experimental CD. The latter consisted of a range of highly palatable human foods (pork pie, pate, cocktail sausages, cheese, crisps, jam, fruit and nut chocolate, golden syrup cake, shortbread and peanuts) ${ }^{(31)}$. Of these food items, four were provided daily and one of those was changed daily. At postnatal day 21, the offspring were weaned, group-housed with littermates of the same sex and maintained on the chow control diet for the remainder of the study.

For behavioural testing, a total of sixteen dams per feeding condition were used and eight pups from each litter were randomly allocated to a testing condition ( $n 10$ per condition). Food consumption of the dams during lactation was closely monitored in an additional eight dams, four from each feeding condition. This was done in independent litters to avoid any possible handling-induced interference with behavioural testing. Energy intake $(\mathrm{kJ})$ and macronutrient consumption (carbohydrates including sugar, fat and protein) were calculated from the manufacturers' data. Weight loss due to evaporation was measured in triplicate samples of each individual food item placed in empty cages. The average daily percentage change in the weight of foods ranged from 0 to $6.2 \%$ and corresponded to an average overestimation of energy intake by $2.51 \%(7.5 \mathrm{~kJ} / \mathrm{d})$, which can be considered within an acceptable error of measurement ${ }^{(31)}$. Body weights of both dams and pups were measured at the beginning and the end of the study.

NOD testing was undertaken between 11 and 13 weeks of age, which is in the range of previous studies related to the subject ${ }^{(26)}$. For behavioural testing, ten pups of each sex were used. The methodology used in the present study was modified from King et al. ${ }^{(32)}$. Briefly, the rats were habituated to the test arena $(54 \mathrm{~cm} \times 38 \mathrm{~cm} \times 40 \mathrm{~cm})$ in the absence of any objects for $1 \mathrm{~h}$ the day before testing. On the day of testing, the rats received an additional 3 min habituation session and were returned to the home cage for $1 \mathrm{~min}$, before being placed into the observation arena for the training (familiarisation) trial with two identical objects for 3-min. In three independent experiments, each rat was then returned to the observation arena for 3 min for the test (choice) trial with one of the two objects replaced by a similar but novel object, either after a 1, 2 or $4 \mathrm{~h}$ inter-trial interval (ITI). The remaining object from the familiarisation trial was left untouched (familiar object). The objects were $150 \mathrm{ml}$ waterfilled plastic bottles with three horizontal stripes of either white or black $1.2 \mathrm{~cm}$-wide masking tape being randomly assigned for each rat during the training schedule. The objects were positioned $13 \mathrm{~cm}$ from the length side and $11 \mathrm{~cm}$ from the width side of the arena in opposite corners. Arena and objects were cleaned with $70 \%$ ethanol between the experiments to eliminate olfactory cues. During the two trials, exploration of each object (sniffing, licking, chewing or approaching the object otherwise at a distance $<1 \mathrm{~cm}$ ) was recorded on a video and later analysed manually using Ethovision 3.1 (Noldus). Testing was undertaken in constant light (80 lux) between 08.30 and 15.00 hours.

The statistical unit for macronutrient and energy intake was the dam. Nutritional data and body weight of dams and pups were analysed using Student's $t$ test. The statistical unit for behavioural testing was the pup. The study was powered to detect a difference of $40 \%$ for the time spent in exploration, based upon $\sigma=4.8$ (determined from published studies) and an $\alpha$ value of 0.5 at $80 \%$ power. Object preferences during each NOD trial were assessed using three-way repeatedmeasures ANOVA (with object as the within-subject factor and diet and ITI as between-subject factors) applied separately to each sex and followed by Bonferroni's multiple-comparison post hoc test. Statistical analysis was conducted using SPSS 21 (IBM) and GraphPad Prism 6 (GraphPad). Values are expressed as means with their standard errors. $P<0.05$ was regarded as statistically significant for all tests.

All procedures were performed under licence from the Home Office, in accordance with the Animals (Scientific Procedures) Act 1986 and after approval from the University of Nottingham Ethical Review Committee. 
Table 1. Daily energy and macronutrient intake in lactating dams

(Mean values with their standard errors; $n 4$ dams per group as collected over $21 \mathrm{~d}$ of lactation)

\begin{tabular}{|c|c|c|c|c|c|c|c|c|c|c|}
\hline \multirow[b]{2}{*}{ Diets } & \multicolumn{2}{|c|}{$\begin{array}{l}\text { Energy intake } \\
\qquad(\mathrm{kJ} / \mathrm{d})\end{array}$} & \multicolumn{2}{|c|}{$\begin{array}{l}\text { Carbohydrate } \\
\qquad(\mathrm{g} / \mathrm{d})\end{array}$} & \multicolumn{2}{|c|}{ Sucrose $(g / d)$} & \multicolumn{2}{|c|}{ Fat $(g / d)$} & \multicolumn{2}{|c|}{ Protein (g/d) } \\
\hline & Mean & SEM & Mean & SEM & Mean & SEM & Mean & SEM & Mean & SEM \\
\hline Chow & $564 \cdot 50$ & 54.00 & $19 \cdot 20$ & 1.84 & 1.75 & 0.17 & $2 \cdot 70$ & 0.26 & $8 \cdot 10$ & 0.77 \\
\hline Cafeteria & $762 \cdot 80^{\star *}$ & $35 \cdot 80$ & $17 \cdot 40$ & 0.86 & $5 \cdot 71^{\star \star \star \star *}$ & 0.52 & $9 \cdot 53^{\star \star \star \star}$ & 0.68 & $6 \cdot 25^{\star}$ & 0.41 \\
\hline
\end{tabular}

Mean value was significantly different from that of the chow-fed controls: ${ }^{\star} P<0.05,{ }^{\star \star} P<0.01,{ }^{\star \star \star \star} P<0.0001$ (Student's $t$ test).

\section{Results}

Lactating CD-fed females had a higher energy intake due to overconsumption of fat and sucrose, although the overall carbohydrate intake was similar to the chow-fed controls. Protein intake was reduced in CD-fed dams (Table 1). Body weight as measured following parturition was similar in both groups (data not shown). The CD-fed dams gained more weight during lactation (29.8 (SEM 1.3) g) than the chow-fed controls $(17 \cdot 8$ (SEm 2.2) g) $(P<0 \cdot 01)$. By contrast, CD feeding did not have an impact on body weight in pups in the present study (data not shown) and in a previous study ${ }^{(26)}$.

Neither male nor female offspring demonstrated any spatial preference for either identical object during the familiarisation trial, and there was no impact of the diet on the total levels of object exploration by either sex (data not shown).

After a $1 \mathrm{~h}$ ITI, male offspring were able to distinguish the novel from the familiar object, regardless of whether the dams received the chow diet $(P<0.001)$ or the CD $(P<0.0001)$ (Fig. 1(a)). After a $2 \mathrm{~h}$ ITI, male offspring from the CD-fed dams distinguished the novel from the familiar object $(P<0 \cdot 01)$, but the controls showed no signs of memory, and neither group exhibited preferential exploration of the novel object after a $4 \mathrm{~h}$ ITI (Fig. 1(a)).

Female offspring from the control dams successfully discriminated the novel object after an ITI of both $1 \mathrm{~h}(P<0.05)$ and $2 \mathrm{~h}(P<0.001)$, but in each case, discrimination was absent in female offspring from the CD-fed dams (Fig. 1(b)). However, there was a tendency in these female offspring from the CD-fed dams to discriminate the novel object after a $1 \mathrm{~h}$ ITI
$(P<0 \cdot 10)$. Taken together, these findings suggest that maternal exposure to the CD during lactation exerts a differential effect on cognitive performance in male and female offspring, with lactational $\mathrm{CD}$ exposure delaying memory decay in males and accelerating memory decay in females. Irrespective of maternal diet, neither sex showed any behavioural signs of memory after a $4 \mathrm{~h}$ interval.

\section{Discussion}

The present study tested the hypothesis that exposure to cafeteria feeding during the suckling period would have an impact on recognition memory in adult life. This was of interest given the previous observations that feeding and anxiety-related behaviours are targets for nutritional programming at this stage of life. Our findings confirmed that lactational CD feeding influenced the learning behaviour of Wistar rats.

The present study demonstrated that offering dams a CD during lactation led to an increased energy intake, largely due to overconsumption of fat and sucrose. We observed reduced protein intake, which has been reported in previous $^{(31,33)}$, but not in all cafeteria, studies ${ }^{(34,35)}$. Although protein intake was significantly lowered by CD feeding, a $23 \%$ reduction was not sufficient to have an impact on pup growth, suggesting that the protein deficit was modest compared with the overconsumption of energy, fat and sugars. We would rather suggest that programming and behavioural effects of diets mimicking a Western-type diet are complex and cannot be attributed to a nutritional imbalance of a single macronutrient.

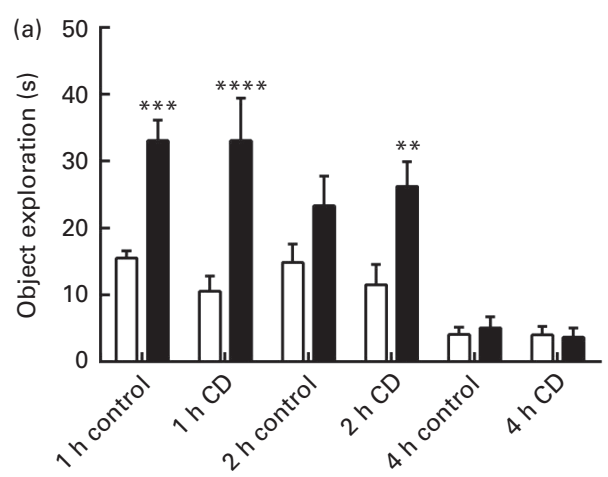

ITI and diet

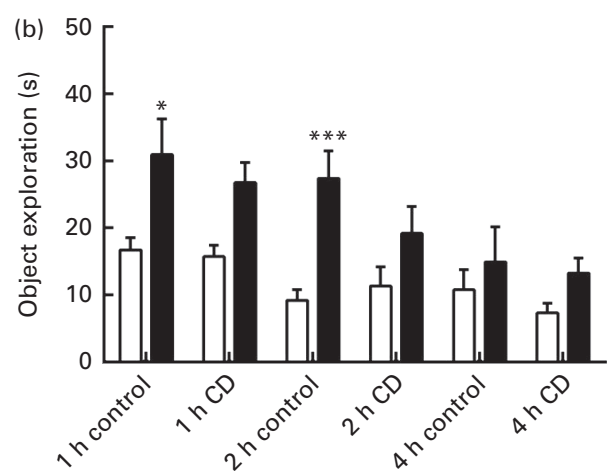

ITI and diet

Fig. 1. Effect of maternal lactational diet on novel object discrimination in adult offspring following an inter-trial interval (ITI) of $1-4 \mathrm{~h}$. Duration (s) spent by (a) males and (b) females exploring familiar $(\square)$ and novel (ם) objects during the choice trial ( $n$ 8-10 per group). Values are means, with their standard errors represented by vertical bars. Mean value was significantly different from that of the familiar object in the same sex following the same maternal diet and ITI: ${ }^{\star} P<0.05,{ }^{\star \star} P<0.01,{ }^{\star \star \star} P<0.001,{ }^{\star \star \star \star} P<0.0001$ (three-way repeated-measures ANOVA with Bonferroni's multiple-comparison post hoc test). CD, cafeteria diet. 
Feeding of a hyperenergetic CD to rat dams during lactation had a significant impact on object recognition memory of the offspring in adult age. This finding provides further evidence that the lactational period is not only important for metabolic programming ${ }^{(25,36)}$, but also for programming of behaviour, as we found both reduced anxiety and reduced behavioural satiety in parallel studies conducted under identical conditions ${ }^{(26,27)}$.

The observed sex differences in chow-fed controls appear to be consistent with previous non-spatial NOD studies, where females proved to be superior to males, although the opposite is true for spatial versions of the test ${ }^{(37,38)}$. Although not controlled for in the present study, oestrogen (E2) has been shown to be associated with better NOD performance ${ }^{(39)}$ and could potentially modulate NOD through interactions with the brain serotonergic system (for a review, see McEwen et $\left.a l .{ }^{(40)}\right)$. Serotonin (5-hydroxytryptamine) plays a role in NOD (for a review, see Dere et $a l .{ }^{(28)}$; King et $a l .{ }^{(32)}$ ) and seems to be affected by early cafeteria feeding as we found in the hypothalamus of the offspring from CD-fed dams ${ }^{(26)}$. Therefore, 5-hydroxytryptamine-oestrogen interactions may account for the observed sex differences in the effect of early CD feeding programming on NOD, although an additional contribution of glucose levels is also possible.

In obese rats, fasting glucose levels are negatively correlated with $\mathrm{NOD}^{(11)}$. Although lactational CD feeding per se only predisposes the offspring to obesity and has a little impact on fasting glucose levels ${ }^{(25,27,31)}$, male rats exposed to $\mathrm{CD}$ feeding in the lactation period show a more rapid glucose clearance in the blood following a glucose challenge, whereas in females, lactational chow leads to faster glucose clearance $^{(25)}$. As exogenous glucose can enhance memory ${ }^{(41)}$ and brain glucose fluctuates depending on local demand ${ }^{(42)}$, it could be speculated that diet-programmed and sex-dependent differences in glucose metabolism/clearance could contribute to the differential effects of lactational cafeteria feeding on NOD learning in male and female offspring.

Maternal obesity, either due to high fat feeding or a sucroseenriched diet, impaired reversal learning in the offspring, regardless of the type of hyperenergetic diet ${ }^{(13)}$. The present study and other studies ${ }^{(22)}$ provide evidence that in rodents, an obesogenic environment in early life has an impact on cognitive functions in adult age. However, the precise outcome, either being positive or negative, depends on diet, memory model and possibly sex. In general, these rodent studies are relevant to the situation in humans where cognitive deficits have been attributed also to maternal obesity ${ }^{(43,44)}$.

In conclusion, the present study shows that maternal exposure to CD feeding can programme NOD in adult life. In better-performing females, dietary programming interferes with NOD, whereas NOD was improved in males after actational CD feeding.

\section{Acknowledgements}

The authors gratefully acknowledge Asli Akyol, Carol Armett, Sarah Kirkland, Richard Plant and Karen Swift for their expert technical support.
The present study was supported by grant RSF5103 (to J.-P. W. V. and S. C. L.-E.) from the University of Nottingham. T. M. W. was supported by an IDTC studentship from the School of Veterinary Medicine and Science and the School of Biosciences, University of Nottingham.

The authors' contributions were as follows: J.-P. W. V. and S. C. L.-E. designed the experiment. T. M. W. and W. G. D. performed the experimental analyses, and collated the data. M. V. K. performed the statistical analyses. J.-P. W. V. wrote the manuscript. All authors discussed the results and commented on the manuscript.

There is no conflict of interest.

\section{References}

1. Stranahan AM \& Mattson MP (2008) Impact of energy intake and expenditure on neuronal plasticity. Neuromol Med 10, 209-218.

2. Winocur G \& Greenwood CE (2005) Studies of the effects of high fat diets on cognitive function in a rat model. Neurobiol Aging 26, Suppl. 1, 46-49.

3. Heyward FD, Walton RG, Carle MS, et al. (2012) Adult mice maintained on a high-fat diet exhibit object location memory deficits and reduced hippocampal SIRT1 gene expression. Neurobiol Learn Mem 98, 25-32.

4. Kosari S, Badoer E, Nguyen JC, et al. (2012) Effect of western and high fat diets on memory and cholinergic measures in the rat. Behav Brain Res 235, 98-103.

5. McNay EC, Ong CT, McCrimmon RJ, et al. (2010) Hippocampal memory processes are modulated by insulin and high-fat-induced insulin resistance. Neurobiol Learn Mem 93, 546-553.

6. Pintana H, Apaijai N, Pratchayasakul W, et al. (2012) Effects of metformin on learning and memory behaviors and brain mitochondrial functions in high fat diet induced insulin resistant rats. Life Sci $\mathbf{9 1}, 409-414$.

7. Beilharz JE, Maniam J \& Morris MJ (2014) Short exposure to a diet rich in both fat and sugar or sugar alone impairs place, but not object recognition memory in rats. Brain Behav Immun 37, 134-141.

8. Valladolid-Acebes I, Stucchi P, Cano V, et al. (2011) High-fat diets impair spatial learning in the radial-arm maze in mice. Neurobiol Learn Mem 95, 80-85.

9. Woo J, Shin KO, Park SY, et al. (2013) Effects of exercise and diet change on cognition function and synaptic plasticity in high fat diet induced obese rats. Lipids Health Dis 12, 144.

10. Davidson TL, Hargrave SL, Swithers SE, et al. (2013) Inter-relationships among diet, obesity and hippocampaldependent cognitive function. Neuroscience 253, 110-122.

11. Jurdak N \& Kanarek RB (2009) Sucrose-induced obesity impairs novel object recognition learning in young rats. Physiol Behav 96, 1-5.

12. Ennaceur A \& Delacour J (1988) A new one-trial test for neurobiological studies of memory in rats. 1: Behavioral data. Behav Brain Res 31, 47-59.

13. Wu T, Deng S, Li WG, et al. (2013) Maternal obesity caused by overnutrition exposure leads to reversal learning deficits and striatal disturbance in rats. PLOS ONE 8, e78876.

14. Bilbo SD \& Tsang V (2010) Enduring consequences of maternal obesity for brain inflammation and behavior of offspring. FASEB J 24, 2104-2115.

15. Rodriguez JS, Rodriguez-Gonzalez GL, Reyes-Castro LA, et al. (2012) Maternal obesity in the rat programs male offspring exploratory, learning and motivation behavior: prevention 
by dietary intervention pre-gestation or in gestation. Int J Dev Neurosci 30, 75-81.

16. Tozuka Y, Kumon M, Wada E, et al. (2010) Maternal obesity impairs hippocampal BDNF production and spatial learning performance in young mouse offspring. Neurochem Int $\mathbf{5 7}$, 235-247.

17. Sclafani A \& Springer D (1976) Dietary obesity in adult rats: similarities to hypothalamic and human obesity syndromes. Physiol Behav 17, 461-471.

18. Rothwell NJ \& Stock MJ (1979) Combined effects of cafeteria and tube-feeding on energy balance in the rat. Proc Nutr Soc 38, $5 \mathrm{~A}$.

19. Rothwell NJ \& Stock MJ (1988) The cafeteria diet as a tool for studies of thermogenesis. J Nutr 118, 925-928.

20. Prats E, Monfar M, Castella J, et al. (1989) Energy intake of rats fed a cafeteria diet. Physiol Behav 45, 263-272.

21. Sampey BP, Vanhoose AM, Winfield HM, et al. (2011) Cafeteria diet is a robust model of human metabolic syndrome with liver and adipose inflammation: comparison to high-fat diet. Obesity (Silver Spring) 19, 1109-1117.

22. White CL, Pistell PJ, Purpera MN, et al. (2009) Effects of high fat diet on Morris maze performance, oxidative stress, and inflammation in rats: contributions of maternal diet. Neurobiol Dis 35, 3-13.

23. Bayol SA, Simbi BH \& Stickland NC (2005) A maternal cafeteria diet during gestation and lactation promotes adiposity and impairs skeletal muscle development and metabolism in rat offspring at weaning. J Physiol 567, 951-961.

24. Benkalfat NB, Merzouk H, Bouanane S, et al. (2011) Altered adipose tissue metabolism in offspring of dietary obese rat dams. Clin Sci (Lond) 121, 19-28.

25. Akyol A, McMullen S \& Langley-Evans SC (2012) Glucose intolerance associated with early-life exposure to maternal cafeteria feeding is dependent upon post-weaning diet. Br J Nutr 107, 964-978.

26. Wright TM, Fone KC, Langley-Evans SC, et al. (2011) Exposure to maternal consumption of cafeteria diet during the lactation period programmes feeding behaviour in the rat. Int J Dev Neurosci 29, 785-793.

27. Wright T, Langley-Evans SC \& Voigt JP (2011) The impact of maternal cafeteria diet on anxiety-related behaviour and exploration in the offspring. Physiol Behav 103, 164-172.

28. Dere E, Huston JP \& De Souza Silva MA (2007) The pharmacology, neuroanatomy and neurogenetics of one-trial object recognition in rodents. Neurosci Biobehav Rev 31, 673-704.

29. Murphy M \& Mercer JG (2013) Diet-regulated anxiety. Int J Edocrinol 2013, 701967.

30. Ross AP, Darling JN \& Parent MB (2013) High energy diets prevent the enhancing effects of emotional arousal on memory. Behav Neurosci 127, 771-779.
31. Akyol A, Langley-Evans SC \& McMullen S (2009) Obesity induced by cafeteria feeding and pregnancy outcome in the rat. Br J Nutr 102, 1601-1610.

32. King MV, Sleight AJ, Woolley ML, et al. (2004) 5-HT6 receptor antagonists reverse delay-dependent deficits in novel object discrimination by enhancing consolidation an effect sensitive to NMDA receptor antagonism. Neuropharmacology 47, 195-204.

33. Warneke W, Klaus S, Fink H, et al. (2014) The impact of cafeteria diet feeding on physiology and anxiety-related behaviour in male and female Sprague-Dawley rats of different ages. Pharmacol Biochem Behav 116, 45-54.

34. Esteve M, Rafecas I, Fernandezlopez JA, et al. (1994) Effect of a cafeteria diet on energy-intake and balance in Wistar rats. Physiol Behav 56, 65-71.

35. Llado I, Pico C, Palou A, et al. (1995) Protein and aminoacid intake in cafeteria fed obese rats. Physiol Behav 58, $513-519$

36. Daniel ZC, Akyol A, McMullen S, et al. (2014) Exposure of neonatal rats to maternal cafeteria feeding during suckling alters hepatic gene expression and DNA methylation in the insulin signalling pathway. Genes Nutr 9, 365

37. Sutcliffe JS, Marshall KM \& Neill JC (2007) Influence of gender on working and spatial memory in the novel object recognition task in the rat. Behav Brain Res 177, $117-125$.

38. Ghi P, Orsetti M, Gamalero SR, et al. (1999) Sex differences in memory performance in the object recognition test Possible role of histamine receptors. Pharmacol Biochem Behav 64, 761-766.

39. Walf AA, Rhodes ME \& Frye CA (2006) Ovarian steroids enhance object recognition in naturally cycling and ovariectomized, hormone-primed rats. Neurobiol Learn Mem 86, 35-46.

40. McEwen BS, Akama KT, Spencer-Segal JL, et al. (2012) Estrogen effects on the brain: actions beyond the hypothalamus via novel mechanisms. Behav Neurosci 126, 4-16.

41. Gold PE (1995) Role of glucose in regulating the brain and cognition. Am J Clin Nutr 61, 987S-995S.

42. McNay EC \& Gold PE (2002) Food for thought: fluctuations in brain extracellular glucose provide insight into the mechanisms of memory modulation. Behav Cogn Neurosci Rev 1, 264-280.

43. Van Lieshout RJ (2013) Role of maternal adiposity prior to and during pregnancy in cognitive and psychiatric problems in offspring. Nutr Rev 71, Suppl. 1, S95-S101.

44. Sullivan EL, Nousen EK \& Chamlou KA (2014) Maternal high fat diet consumption during the perinatal period programs offspring behavior. Physiol Behav 123, 236-242. 